\title{
Approaches for Solutions of Housing Crisis for the Mohammadpur Geneva Camp
}

\author{
Masud Ur Rashid* \\ Department of Architecture, Southeast University, Bangladesh
}

Submission: July 17, 2020; Published: September 28, 2020

*Corresponding author: Masud Ur Rashid, Department of Architecture, Southeast University, Bangladesh

\begin{abstract}
The five decades old Geneva camp in Dhaka is overcrowded as they have no chance of living outside of the camps because of their statelessness. The camp is a densely-populated settlement having its own natural physical growth is now considered as a long-term settlement rather than temporary holding facilities. This brings a lot of physical, socio-cultural and economic crisis within the settlement. The purpose of this paper is to find out some solutions to mitigate the crisis for housing through some architectural design approach to camp design. The findings are come out by three syntheses through a design exercise by undergraduate level students. Findings show the possibilities of mitigation of existing challenges in socio-cultural as well as physical environment. The study contributes to the literature by developing and proposing a conceptual framework to camp design. It also suggests an evolutionary perspective of camp design. The results can support improvements in camp design, thus alleviating suffering for both refugees and host communities, particularly in developing countries.
\end{abstract}

Keywords: Camp design; Compact settlement; Geneva camp; Housing crisis; Low-income settlement

\section{Introduction}

The term "Housing" comes from the term "House". House is one of the five basic needs of human being. A house is a building that functions as a home for humans. A home is a dwellingplace used as a permanent or semi-permanent residence for an individual, family, household or several families in a tribe. It is often a house, apartment, or other building, or alternatively a mobile home, houseboat, yurt or any other portable shelter. Homes typically provide areas and facilities for sleeping, preparing food, eating, recreation, social and hygiene for the physical and mental wellbeing of the inhabitants. A homestead also includes agricultural land and facilities for domesticated animals [1,2].

The design of housing block is without doubt one of the most interesting and attractive subjects of contemporary architecture. This is because architects face some of the most conflicts generated by present-day society: the problem of high density developments in large cities, the shortage of development land and degradation of quality of life due to factors like social security, acoustic and environmental pollutions, energy crisis and so on. During the second half of the $20^{\text {th }}$ century, the use of vertical construction has proven to be the most logical and effective solution. However, real estate speculation has led to some new serious problems too. In face of face of this situation, worldwide architects are beginning to come out in favour of the recovering quality and dignity in presentday society. Scattered attempts to house the poor has mostly been unsuccessful and no remarkable achievement has been seen. It is high time to come up with a multi-disciplinary action to address low income housing issue [3].

Kennedy [4] defined a refugee camp as "a planned and specially-constructed settlement for a number of displaced households significant enough to also need dedicated nonresidential buildings as part of the planned settlement," while Pan [5] described it as a "spatialization of exception." The traditional camp design approach is to set up "a temporary space in which refugees may receive humanitarian relief and protection until a durable solution can be found to their situation." [6]. But the studied Geneva camp is almost five decades old and it demands some permanent solution now for its inhabitants. Camps increasingly provide long-term accommodation, such as in Dadaab (Somalis), Lebanon (Palestinians), and Algeria (Sahrawi), and are now considered human settlements that continuously change [711]. Kleinschmidt [12] suggested that governments should stop thinking about refugee camps as temporary places. Kennedy $[4,13]$ claimed that because camps are much more long-term than assumed, a standardized approach is not effective due to different cultures and situations.

Geneva camp in Dhaka's Mohammadpur is a colony of the stranded Pakistanis who migrated to the then East Pakistan from the Indian state of Bihar during the partition of 1947.The Urduspeaking Muslims have been living there since the end of the 1971 War of Liberation $[14,15]$. The camp, one of the 70 camps all 
over Bangladesh, is a densely-populated settlement of more than one lakh Biharis where each family with eight to 10 members on average lives in one room, and around 90 people share a latrine [16].

\section{Background}

The Geneva camp is consisting of total 14.5 acres of land. The total settlement is distributed into 9 blocks (Figure 1). This blocks acts to identify the households for the community facilities. Though they are not works properly. The land on which Geneva camp is built is owned by the Liaquat Housing Society. It is one of the few Camps where the land is still privately owned. Although Geneva camp is located on private property, no rent is paid to the Liaquat Housing Society, as the community was considered internally displaced until the Dhaka High Court made its definitive decision in 2008 [17].

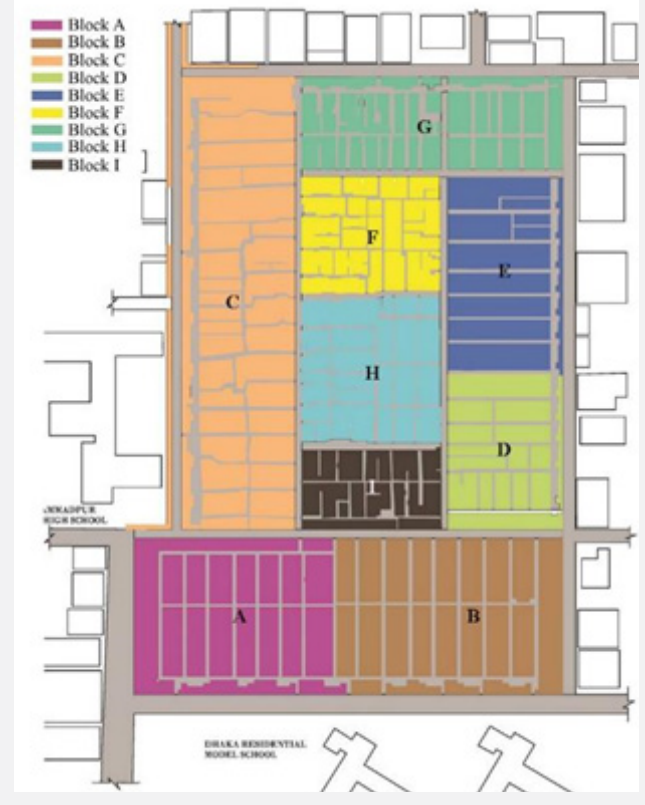

Figure 1: Division of nine blocks inside the camp (Source: Rashid, 2020).

More than 30 thousand people live in this camp. The density is 2100 person per acre which is beyond any housing standard of the world. there are 3843 houses (respondents' information) to accommodate this population. The over populated camp is like an island in the city (Figure 2). The inhabitants have no way to escape. They have to adjust their houses inside this confined settlement. It is highly crowded and the environmental scenario is hazardous. There is inadequate supply of basic facilities like water, electricity and gas. According to UN-HABITAT slum housing is 'households that lack decent water supply, adequate sanitation facilities, sufficient living area, decent structural quality and/or security of tenure' [18].

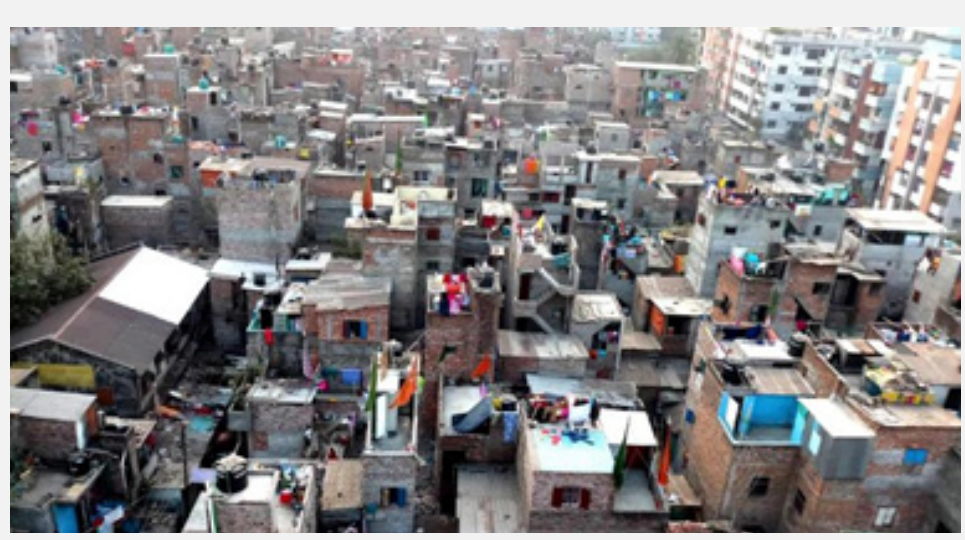

Figure 2: Panoramic view of Geneva camp. (source: Field survey, 2019). 
There are still dwellings with eight by six square feet area for eight to ten family members. Lack of access to water and poor sanitation are problems in every camp. Only two hundred toilets serve thousands of people and most of them are dirty and have no doors. Unclean water infects children with water-borne diseases; urinary tract infections affect women and girls. The lack of access to clean water makes it difficult for the people to maintain proper hygiene. The Geneva camp is a compact and confined living place for its inhabitants. Besides houses there are commercial activities, bazar, small retail shops and cottage industries, community clubs, restaurants, two large mosques and numerous small shrines, as well as two schools and a medical clinic run by the communitybased NGO Al-Falah Bangladesh and some other social spaces inside the camp. Following figure shows different type of spaces or built forms in the existing layout plan of the camp (Rashid, M. 2020).

Adequate shelter means more than a roof over one's head. It also means adequate privacy; adequate space; physical accessibility; adequate security; adequate basic infrastructure, such as water-supply, sanitation, and waste-management facilities; suitable environmental quality and health-related factors; and adequate and accessible location with regard to work and basic facilities: all of which should be available at an affordable cost (Rashid, M. 2020).

The camp plays an important role in social categorization of these Urdu speaking people. Geneva camp is not only associated with its past but the location of the camp and socio-economic situation of the camp dwellers also put them in a separate box while comparing with non-camp people. All the camps were highly crowded and the environmental scenario was hazardous. There was inadequate supply of basic facilities like water, electricity and gas. Besides some political and social issues, following are the major problems found by this study need to be addressed to improve the physical living condition of the Geneva camp:

a) Living space is too small for a family. Living in a tremendously small space creates many other subsequent problems.

b) Drainage and sanitation is in very poor condition. Improper drainage and sanitation is the cause of many diseases and unhealthy living condition.

c) Improper waste management is the cause of an unhealthy and unhygienic living environment. The overall camp is like a place with garbage.

d) Drinking water is not easy accessible to all of the camp dwellers.

e) There is lack of safety and security inside the camp. The narrow and open stairs, open electric line is dangerous for all, especially for kids. The whole camp is in a vulnerable situation in terms of fire hazard.

f) Green and open space is not sufficient. For a better living these are necessary.

g) Education and Health both are inadequate for the camp dwellers.

\section{Methodology}

This study is an outcome of an under-graduate study of sixteen students of Architecture Department of the Southeast University of Dhaka, Bangladesh took place in the year 2019. The study conducted as a part of the Design Studio under the supervision and leadership of the author with the following objectives:

a) To give insight into urbanism and housing, traditional ways of community living, contemporary housing trends and deficiency, trending new concepts and immerging issues in housing sectors.

b) To come up with some pragmatic architectural solutions to mitigate the housing crisis as well as the socio-economic problems of the specific community settlement.

c) Learning from different real life facts and theories and concepts of architecture in housing and exercising the learning outcomes in practical design problems

This article is the second part of the studio outcome whereas the first part is the analysis of the present housing problems of the specific settlement of Geneva camp at Mohammadpur. The problem analysis part has already been published in Rashid, $\mathrm{M}$ (2020). The second part is a design exercise within the studio of sixteen students throughout a fourteen weeks' duration. The students are divided into four groups to continue the design exercise where the author acted as the supervisor for every group. The design exercise was done in three different phases after the site analysis part. The first phase was the 'program development and case study phase' where students developed a comprehensive program for the design and studied different low-cost housing projects around the world to receive ideas about the solution. The second phase was the 'design phase' where students do their design considering various aspects. The considerable aspects are satisfying the housing requirements, maintain housing standards, obeying different building codes for safety and security etc. are mentionable. Above all the architectural aesthetics are also considerable factor to find out the solutions. The third phase was the 'presentation phase' where students had to present their works in front of a jury board.

The specific site for the design exercise is located inside the residential area of Mohammadpur of Dhaka city. Total volume of the site is 14.4 acres (Figure 3). Geneva camp is a place for the URDU speaking community. The community people are Muslim with a different perspective of religious view [19]. Keeping their 
existing religious essence will be a notifiable character of this site. Total population for the settlement would be around 30 thousand with almost five thousand families. The others facilities are - a mosque, community centre, clubs, workshops for the inhabitants, health clinic, schools for children, bazar, commercial zone and parking facilities. Like any other housing project, the main concerns are:

a) Basic functions \& zoning within a house

b) Physical and nonphysical environment of a dwelling unit

c) Social attribute of dwelling unit

d) Dwelling unit typologies (sizes, income group) e) Spatial Organization \& hierarchy of spaces in neighbourhood

f) Density

g) Network of circulation and accessibility

h) Privacy and safety

i) Affordability

j) Social facilities like education, healthcare, shopping, play area, religious, entertainment.

k) Policy and finance of housing.

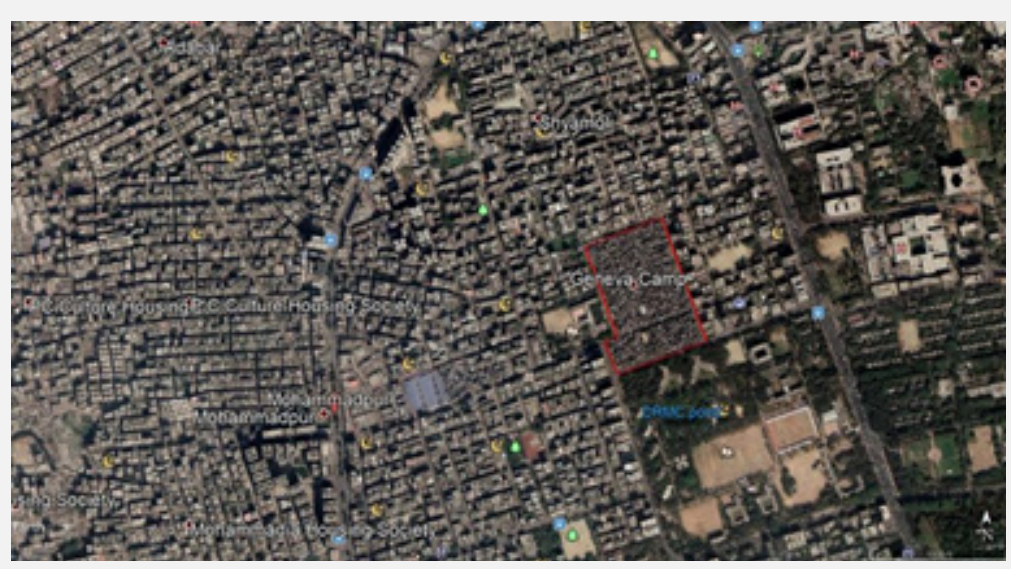

Figure 3: Satellite view from Google Earth view of Mohammadpur Geneva camp.

\section{Present Condition of the Settlement}

Housing is a paradigm that interconnected with many attributes. In the settlement of Geneva camp, the crisis of housing is related to such many attributes. As the population density is very high the living environment of the camps is very deplorable. It is unhealthy, dirty, damp and un-hygienic. Most of the houses consist of one room. Some of the inhabitants reside in multiple storied buildings. They have one room in each floors. The staircases of these multi storied buildings are so narrow that it is impossible for more than one person to climb at a time. Leading a family life in such a small space is really difficult. In half of the families. threegenerations live under the same roof.

The entire camp people share a few common bathrooms and toilets, which are very few compared to the number of people. Most of the time they need to queue to get their turn. Furthermore, both male and female alike share the same facility, which creates problems for the females. There is no privacy for the females either in toilet or shower facilities. There is no house that have a proper sewerage system. There is no septic tank for the private toilets. The solid and liquid both sanitary wastes goes to the surface drain.
Many people had a few ideas about personal hygiene. Densely populated environment, filthy water and lack of proper sanitation cause various disease inside the camp.

There are merely any dedicated social or community space inside the camp. The roads are the main place for community gatherings. Doorsteps inside narrow aisles are the place for social interaction for the dwellers. Camp side roads and in front of different community spaces are also acts as social activity spaces. Most of the internal pathways are 3 to 6 feet wide pedestrian. These narrow pedestrians are like web all over the camp. Sometime buildings from both side are extended over the narrow pathways. Survey shows that total roads and paths occupy $13 \%$ land of the whole camp. These $13 \%$ spaces are the only breathing space for the community.

Family size varied in the population of Geneva camp. Most of the families are joint by nature. There are $68 \%$ of the 400 respondents are living in a joint family and $29 \%$ are living in single or nuclear family. There are few respondents found who are bachelor and live as tenants inside the camp. All the inhabitants of the Geneva camp are Muslim. Though there are two type of believes among them. 
Majority belongs to the belief of Sunni Muslims. It is found by the field survey that there are $96 \%$ people have the belief of Sunni and only $4 \%$ have the belief of Shia. Though by seeing the activities and religious festival of Ashura outside people thing them as Shia believers.

One of the major occupations of the respondent is handicraft, which includes different type of boutique works, tailoring, karchupi and related work. Most of the family members including women and children are involved in income generating activities such as in various handicrafts, shop keeping and selling homemade food item. It is found by the field survey that $19 \%$ camp inhabitants have their workplace inside or adjacent to their living place and another $47 \%$ camp inhabitants works inside the camp. $34 \%$ people have their workplace outside the camp. (Rashid, 2020). As livelihood is a great challenge for the camp inhabitants many of them are involved for different income generating activities. In the roadside houses, the ground floors are used as a shop or other commercial spaces in most of the cases. People are using their living place for some periodic activities also. The same place of sleeping is used for income generating actives at day time.

\section{Design Considerations}

The objectives to achieve by this specific project are as follows:

a) To minimize the acute housing problem with maximum accommodation in a planned way in a healthy environment.

b) Improve the access of the community to education and employment opportunities.

c) Preserve the cultural heritage of the community.

d) Ensure recreational facilities for camp people specially for children.

e) To provide urban facilities with modern amenities, such as affordable shopping support, parks, open space, health clinics, sewerage system, electricity and recreational facilities.

f) Improvements in the Camp inhabitants' living conditions and their feelings of residential security that enables them to have the confidence to invest time and resources into improving one's home environment.

The Camp is isolated from the surrounding urban environment. Its dwellers do not have much interaction with the neighbouring dwellers and other outsiders. It is found that outsiders of the camp do not have much interaction with the camp dwellers. Outsiders are not willing to pass through the Camp. This hinders social interaction which is important for socio-cultural and economic development. In the proposals, attempts have been made to create some spaces and circulation corridor such that neighbourhood residents or outsiders can use them and thereby enter the camp premise. This will eliminate their invisible barrier between making interaction with the dwellers on daily basis and increase sharing and social interaction. Elimination of social barrier is a concept to develop the housing and overall design of the camp. The design strategies are as follows:

a) Quality of liveability - Infill of new amenities.

b) Creation of defined open spaces.

c) Road widening and providing hierarchal connectivity with open spaces.

There are some other important considerations for the design exercises are:

To Improve Economic Condition: Most of the residents being descendants of original refugees fail to get a job or start a business's they are in a very poor economic condition. These leads to crimes and other illegal activities. To make them self-employed they do various kind of small works like paper packaging, weaving sarees, do embroidery works etc. All times they also open small shops to make their earnings. Allocation of shops and economical spaces on the ground floor along the newly developed circulation can create opportunity to start-up small businesses. There are classrooms for vocational training where both men and women to take part and increase their professional skills. Considering provision of economic activities, in the design shops as well as spaces for eco activity have been provided.

To Improve Environmental Condition: To ensure minimum natural light and air flow building modules need to be crated with the provision of at least one side to be open and have windows. The modules are moved in a way that there will be no more critical modules and also create connected terraces which will act as social spaces where internal social interactions will take place. To Create Multifunctional Domestic Spaces: Domestic spaces provides shelter and security for the basic physical functions of life and also for commercial, industrial or agricultural activities that involve the family unit rather than the community. As space is very limited in Geneva camp, multifunctional use of domestic spaces is suitable solution. The same place can be used for different functions in different time.

\section{Design Synthesis}

There were three solutions came out through the design exercise. They are named as Syntheis-1, Syntheis-2 and Syntheis-3. The design objectives are addressed in different manner by those.

\section{Synthesis 1}

The concept is palm and fingers. Where all the fingers are connected with palm (Figure 4). The palm is the heart of the housing. All the housing clusters are connected with the heart (Figure 5). All the major roads are directed to the heart of the housing. In this heart the community facilities are accommodated. And at the centre of the heart it is the mosque. the mosque and the road circulated by it, is the place for the annual religious festivals. 
At the second tier of after the centre the school and community health centre are located. On the third tier the commercial spaces e.g. boutique shops, bazar, restaurant kiosks. The commercial zone and restaurants are also well accessible for the people outside the community, that's why a parking lot is adjacent to this zone.

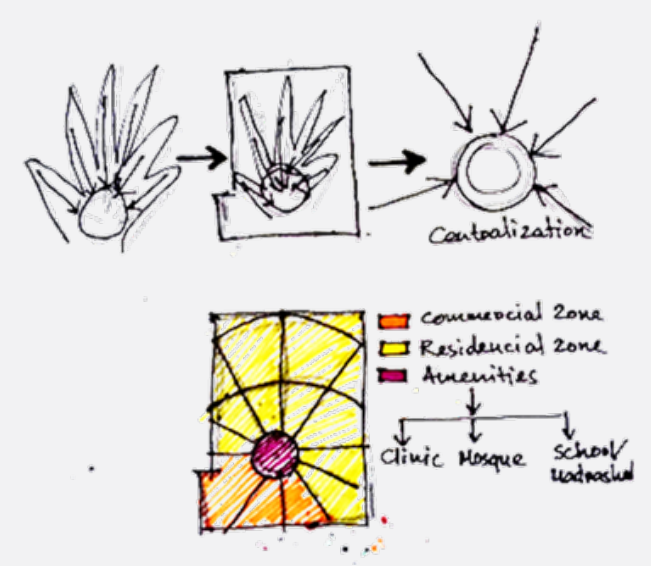

Figure 4: Concept of the Synthesis-1.

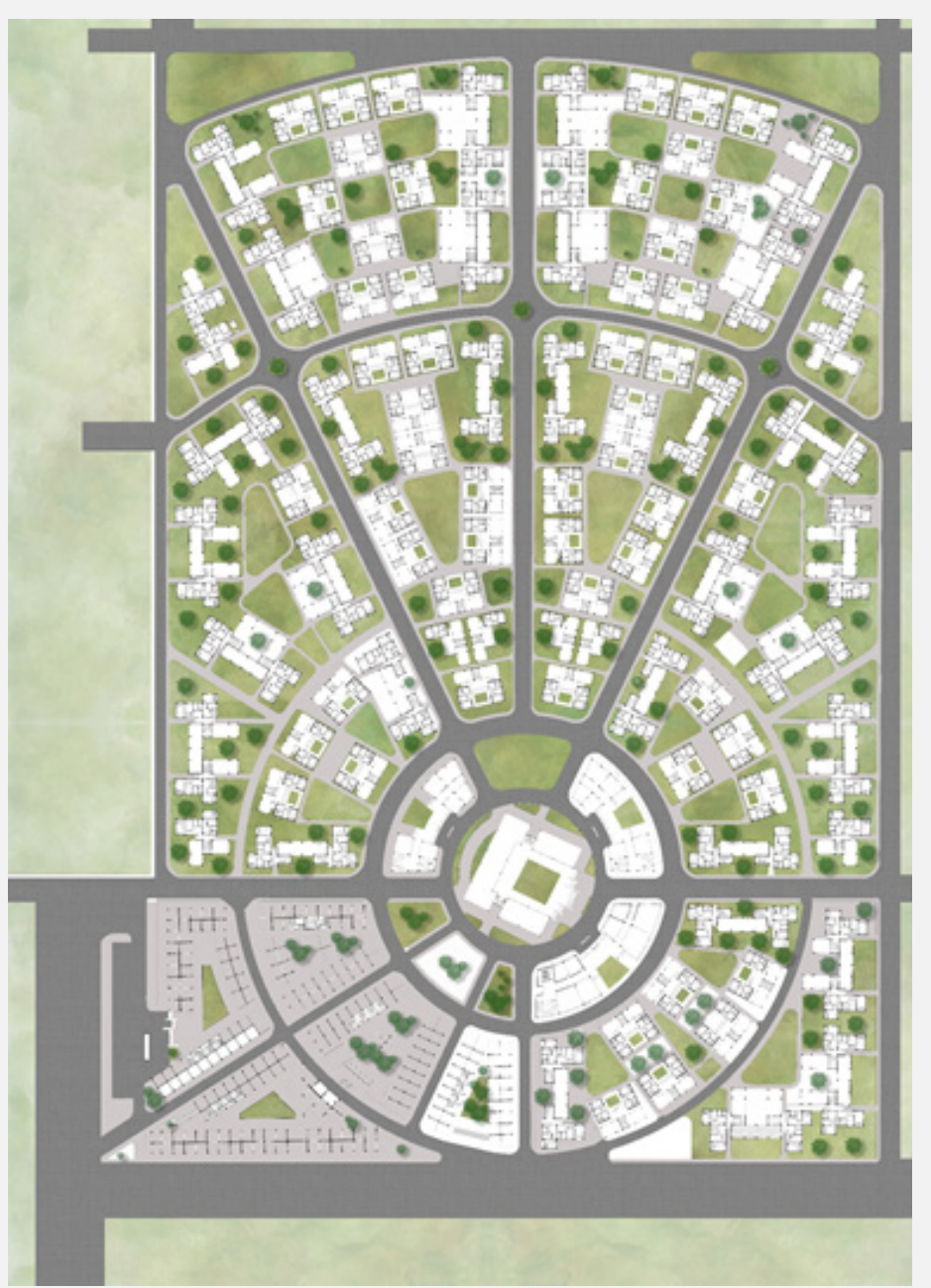

Figure 5: Master plan of the Synthesis-1 (Source: Studio works ). 
The cluster is developed by arrangement of some building blocks keeping some open spaces among them (Figure 6). The building is developed by joining some module of basic living units. Each units stands for a separate family. For creating options for different family size, each building contains multiple type of units.

The typical floor of the buildings has four numbers of apartment unit. There are two general type of combination of two type of living units. One is 500 Square feet and another is 350 Square feet in size. A unit of 500 square feet is consisting of two bed rooms, one dining cum living space, one kitchen, one toilet and one veranda. A unit of 350 square feet of consisting of one bed room, one dining cum living space, one kitchen, one toilet and one veranda (Figure 7).

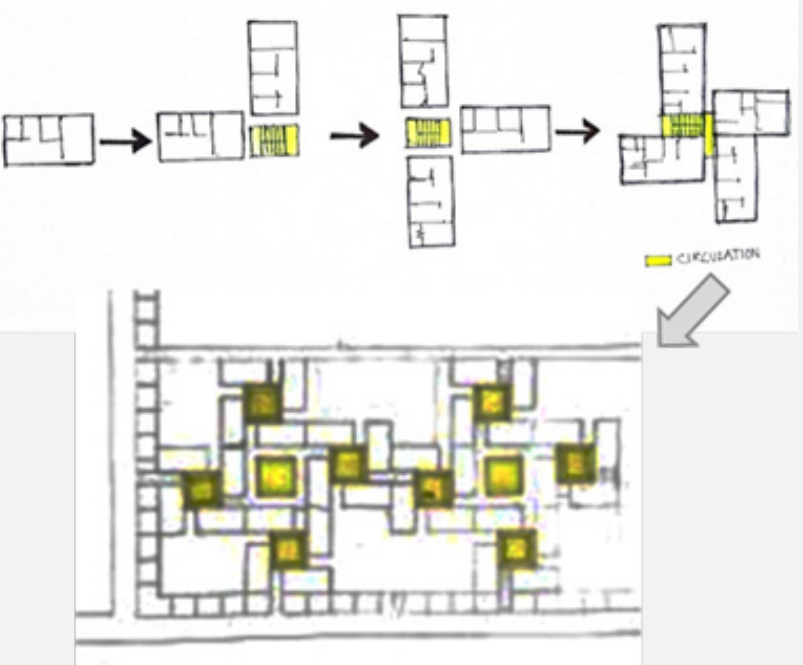

Figure 6: Development of a cluster and building block from basic living units.
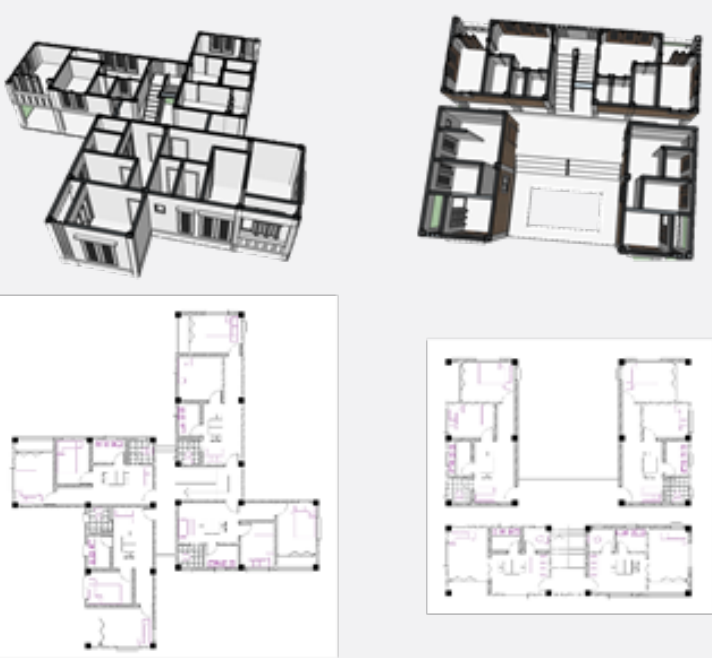

Figure 7: Two different types of building plan with the combination of living units.

Most of the buildings are 5 to 6 storied height where a most of the ground floor spaces remain vacant for the boutique workshop and social activities. These are merged with the opento-sky courtyards (Figure 8). These are semi-private courtyards for the inhabitants of the surrounding building blocks (Figure 9). All the major roads are directed to the central community zone, where the mosque is in the centre and the school, health centre and other community spaces are located (Figure 10). The central 


\section{Trends in Technical \& Scientific Research}

community zone has the provision for gathering of huge people during the time of annual festivals like 'Ashura'. By this approach of design, $17 \%$ of the total space is required for the roads. There are $37 \%$ space is open which includes courtyards, roads, vegetable gardens, roads and other open spaces and $63 \%$ areas are covered by buildings. $20 \%$ of total spaces is soak-able green in this concept (Figure 11).
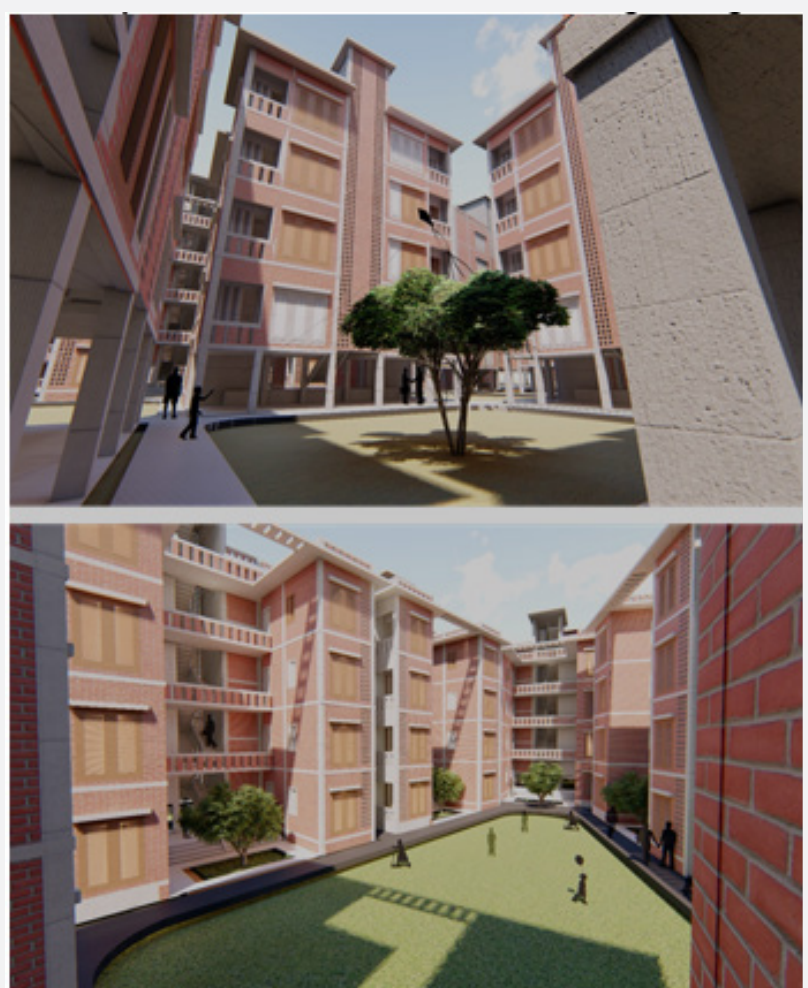

Figure 8: Open to sky courtyard inside the cluster.
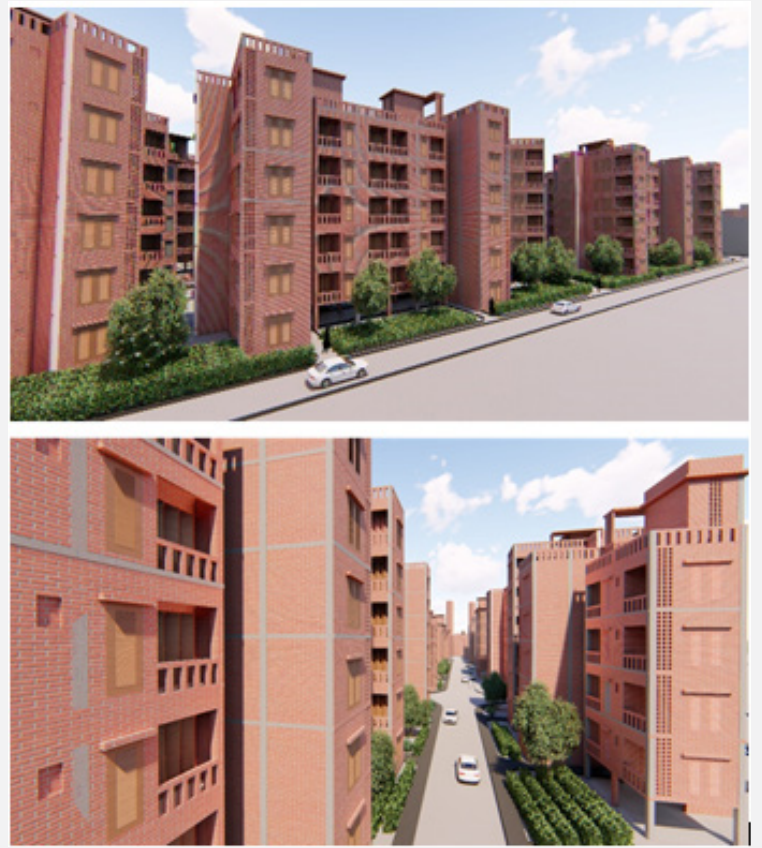

Figure 9: Road side set back and vegetable garden. 


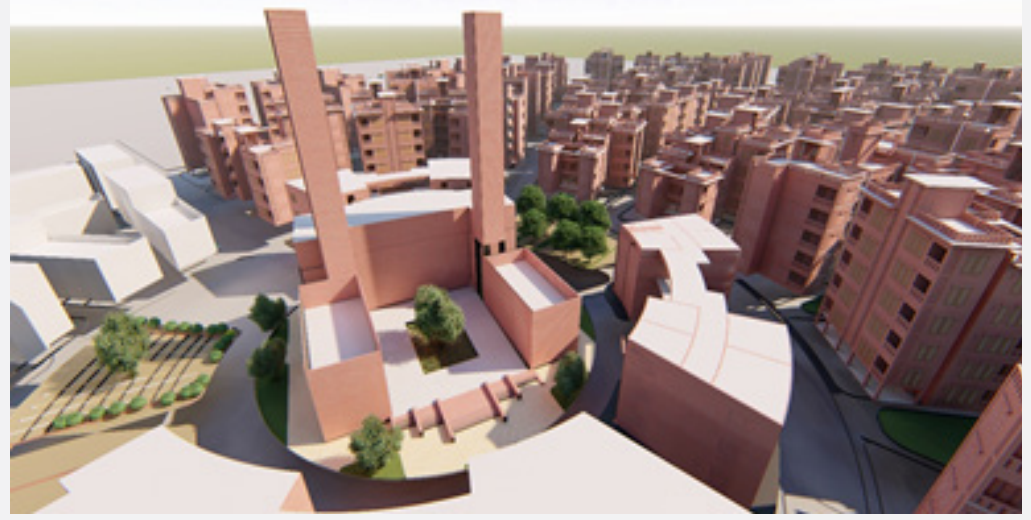

Figure 10: Mosque and community zone at the centre of the housing.

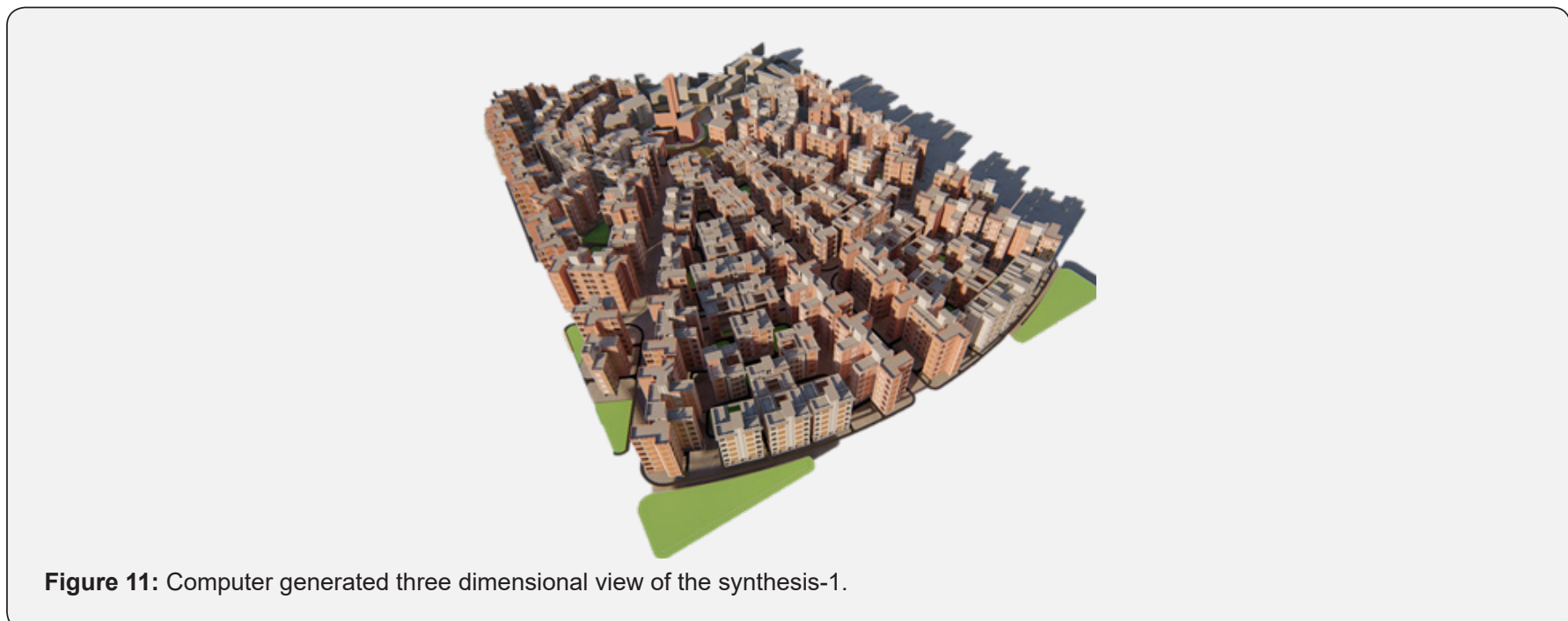

\section{Synthesis 2}

The whole master plan (Figure 12) is organized respecting the climatic orientation. The tilted main Artery roads are connected the main blocks of the housing with the surrounded roads of the neighbourhood. Commercial zones like boutique shops and bazaar are distributed in three locations of the site to establish a connection between the housing and the neighbourhood. The mosque and other community facilities including a play field are located at the centre block. Other than the main artery roads the whole complex is considered as pedestrian and motorized vehicle free which gives the community a peaceful space for living. The school is positioned near by the community block to get easy access from all housing clusters.

The project is designed as a high density settlement to overcome the challenges of the limited land but also to create a high quality urban space derived from a largely natural developed traditional space. Connectivity with the surroundings is an important feature for this approach (Figure 13). Beside considering maximization of connectivity the vehicular roads are also kept in optimum amount and pedestrian pathways are used to connect maximum building blocks. Basic residential buildings are developed by arranging four living units in a linear manner and multiple buildings are connected side by side to form the cluster (Figure 14). This approach can reduce the structural coasts. The linear cluster organized following the shape of ' $L$ ', ' $U$ ' and ' $O$ '. It works the periphery of the courtyard (Figure 15).

The living units are two types. One type is consisting of 302 square feet and another one is 264 square feet. They are organized in a way to reduce the circulation space by minimizing the corridor area (Figure 16). 


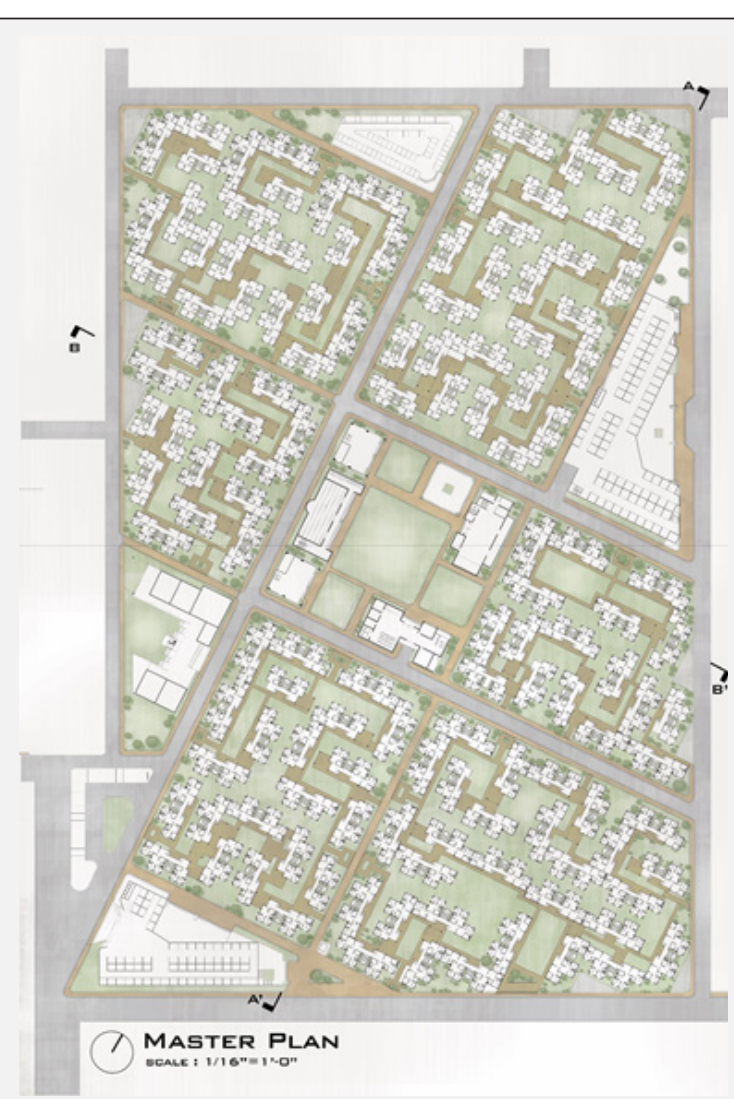

Figure 12: Master Plan of the synthesis-2.

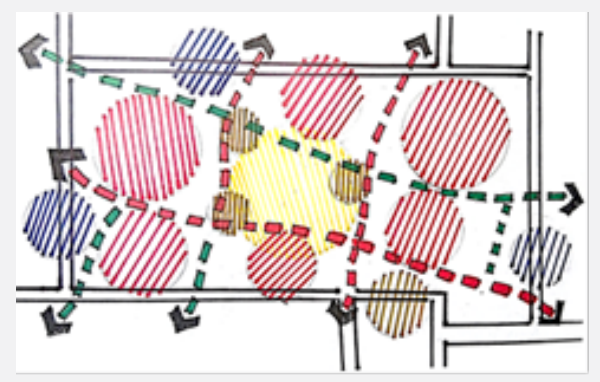

(A)

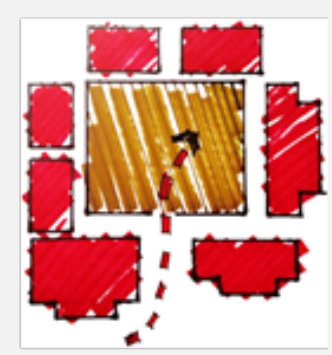

(B)

Figure 13: Connectivity diagram (A) in Master plan and (B) in Housing Cluster.

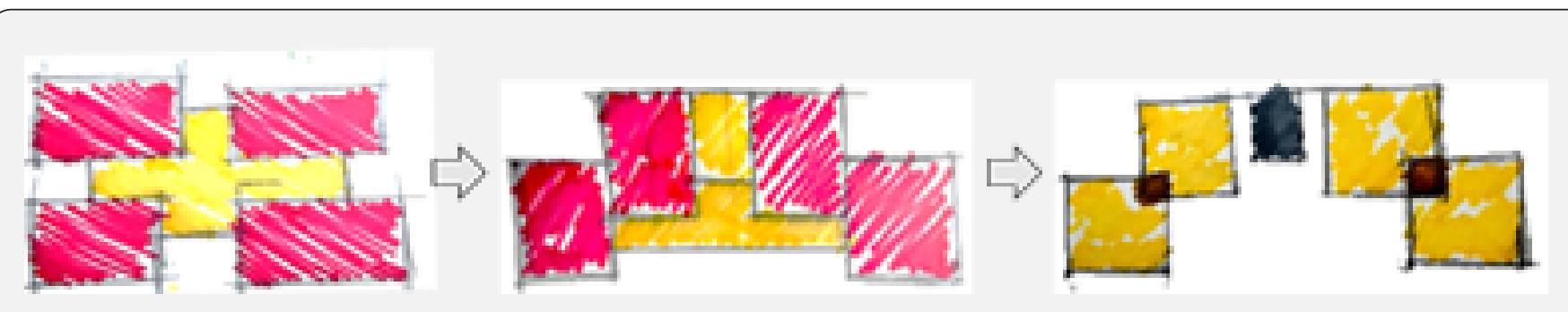

Figure 14: Generation of unit organization by four basic living units. 


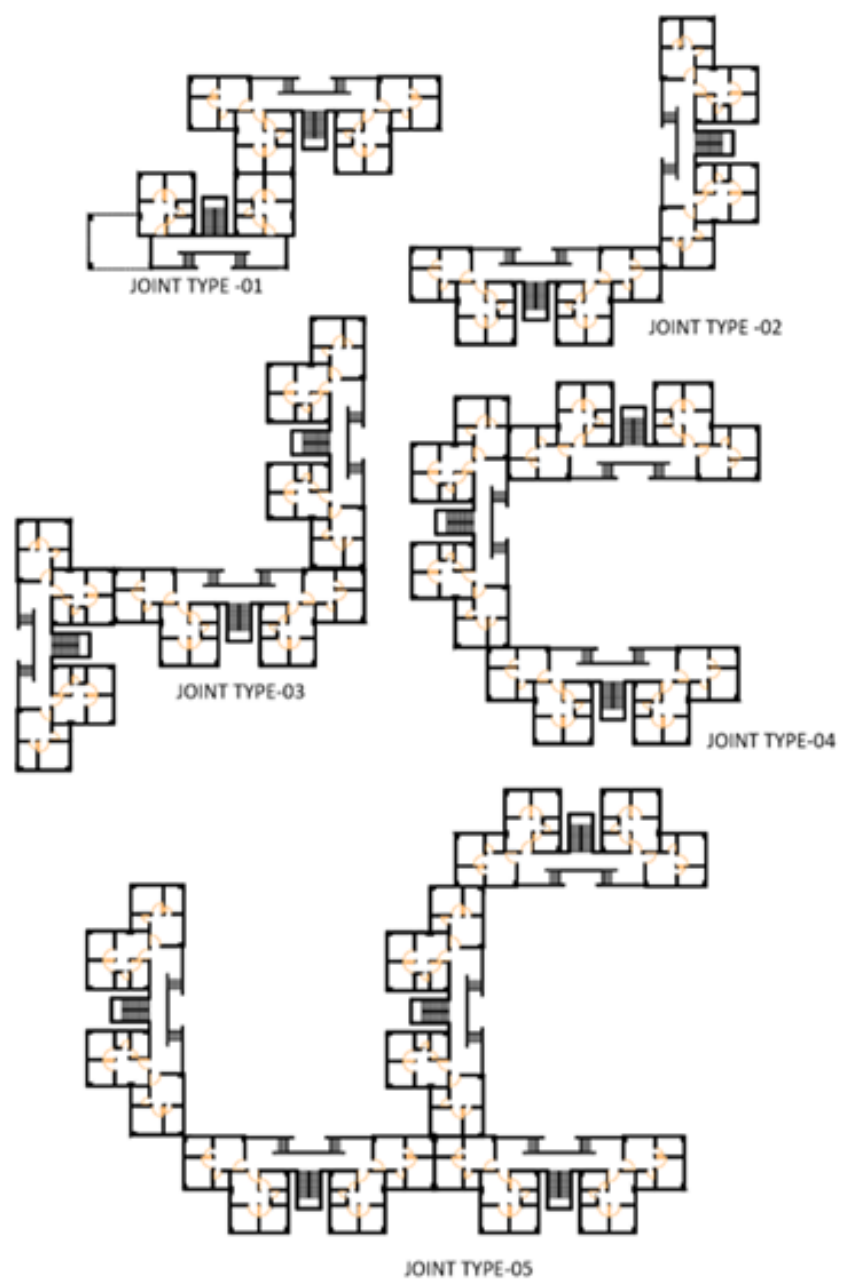

Figure 15: Combination of the basic linear cluster in different ways.

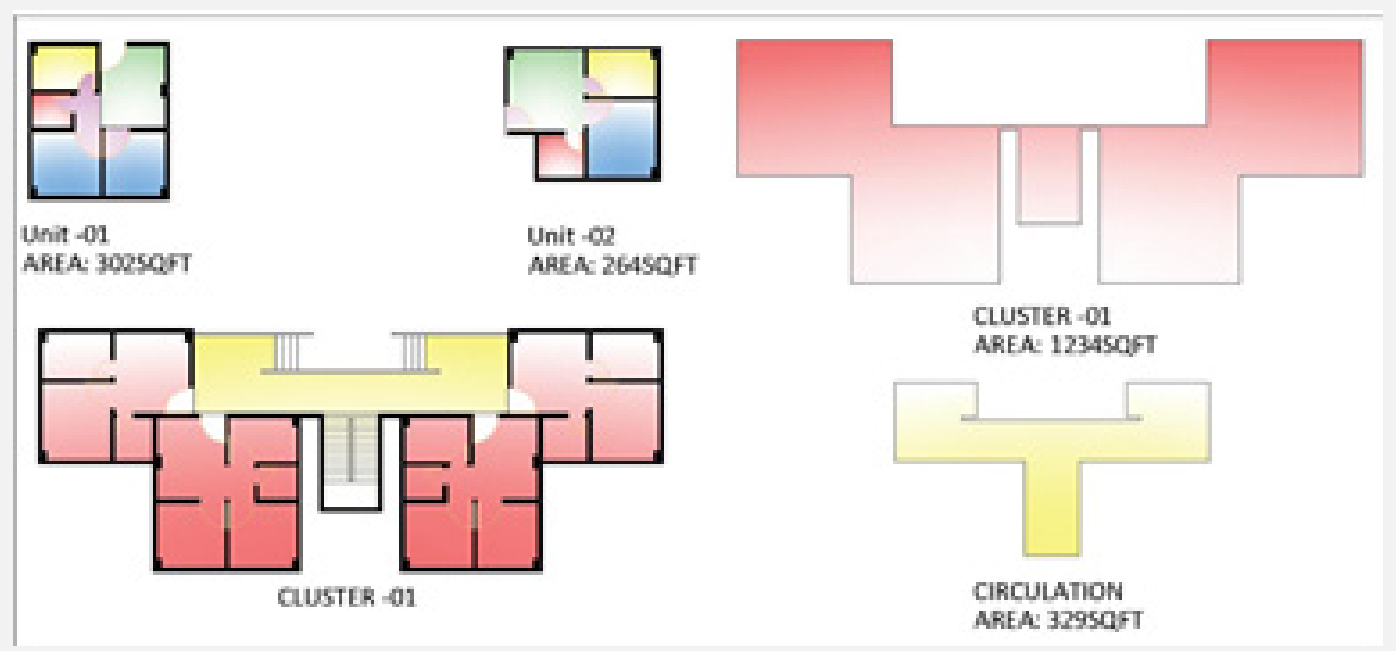

Figure 16: Net living unit area and the circulation in a modular plan. 
It is important to keep in mind the socio-economic aspects of the inhabitants of the camp. All buildings have some communal space and space for workshop within them. These are at the ground floor level (Figure 17). These spaces are merged with the courtyard of the clusters. The workshops are to be used for the household income generating activities for the dwellers. Besides the ground level, the roof tops also considered to use for the social activities and leisure (Figure 18). By this approach of design, 15\% of the total space is covered by the roads. There are $30 \%$ spaces is considered as green spaces which includes courtyards, garden, plantation beside roads etc. (Figure 19).

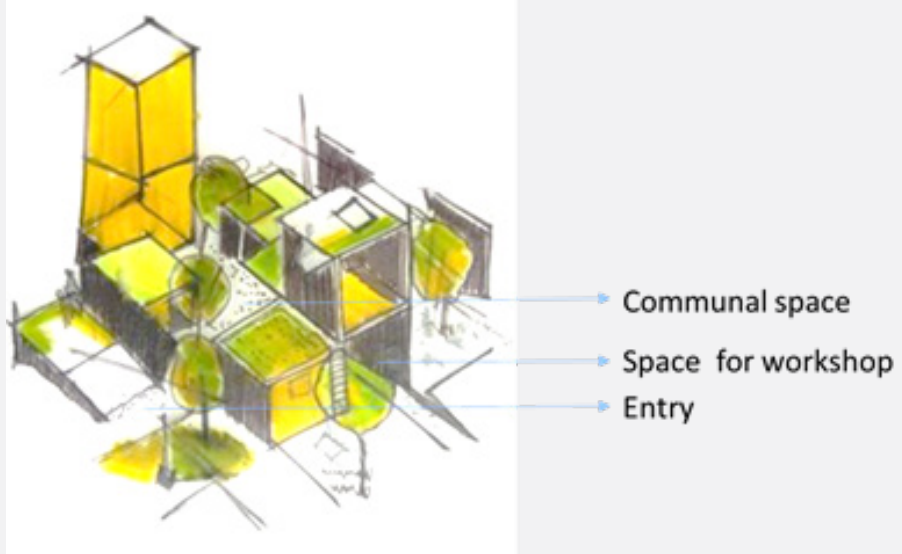

Figure 17: Concept of the basic social spaces inside the building.

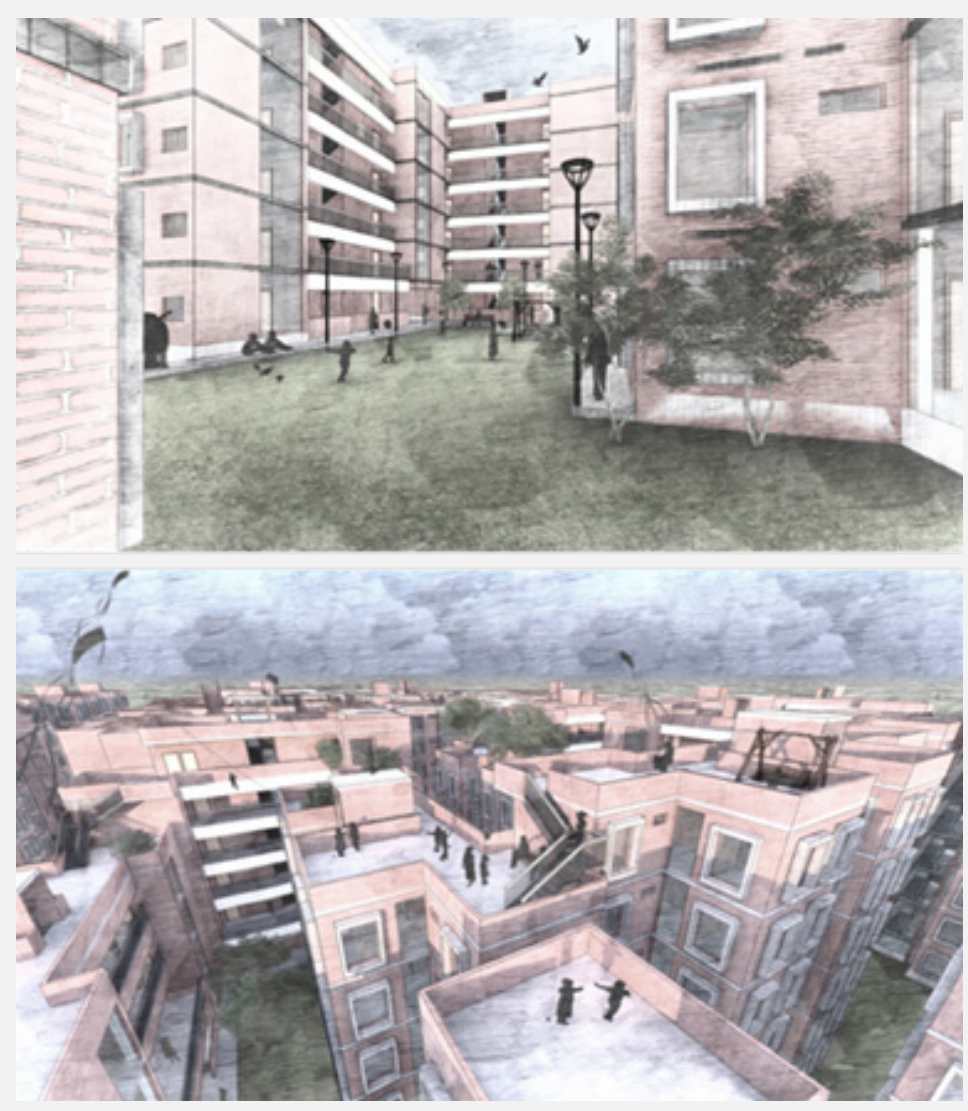

Figure 18: Courtyard and the roof top is to be used as community and leisure activities. 


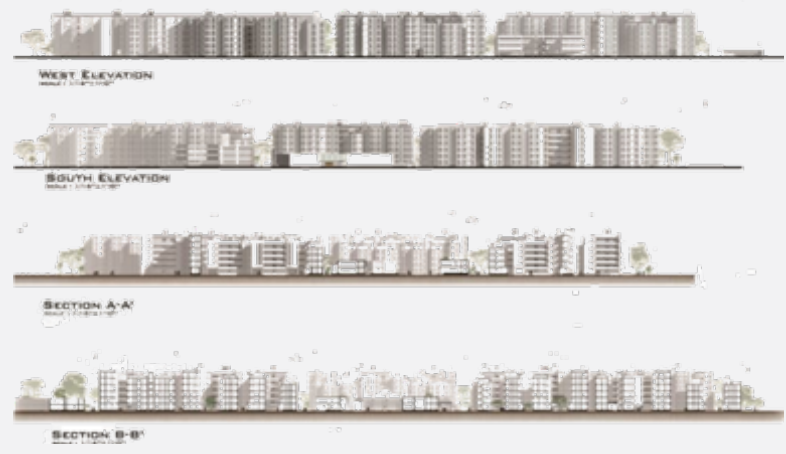

Figure 19: Sections and Elevations of the whole complex.

\section{Synthesis 3}

In this synthesis (Figure 20), the housing clusters are distributed in grid-iron pattern keeping the mosque complex at a central nucleus block. All clusters have their own courtyard with soak-able green space. And group clusters have their own playfield for children. This a hierarchy of open spaces is maintained. Commercial block is separated from the housing block. It is positioned as a ribbon that adjacent to the neighbourhood main road at South side of the site.

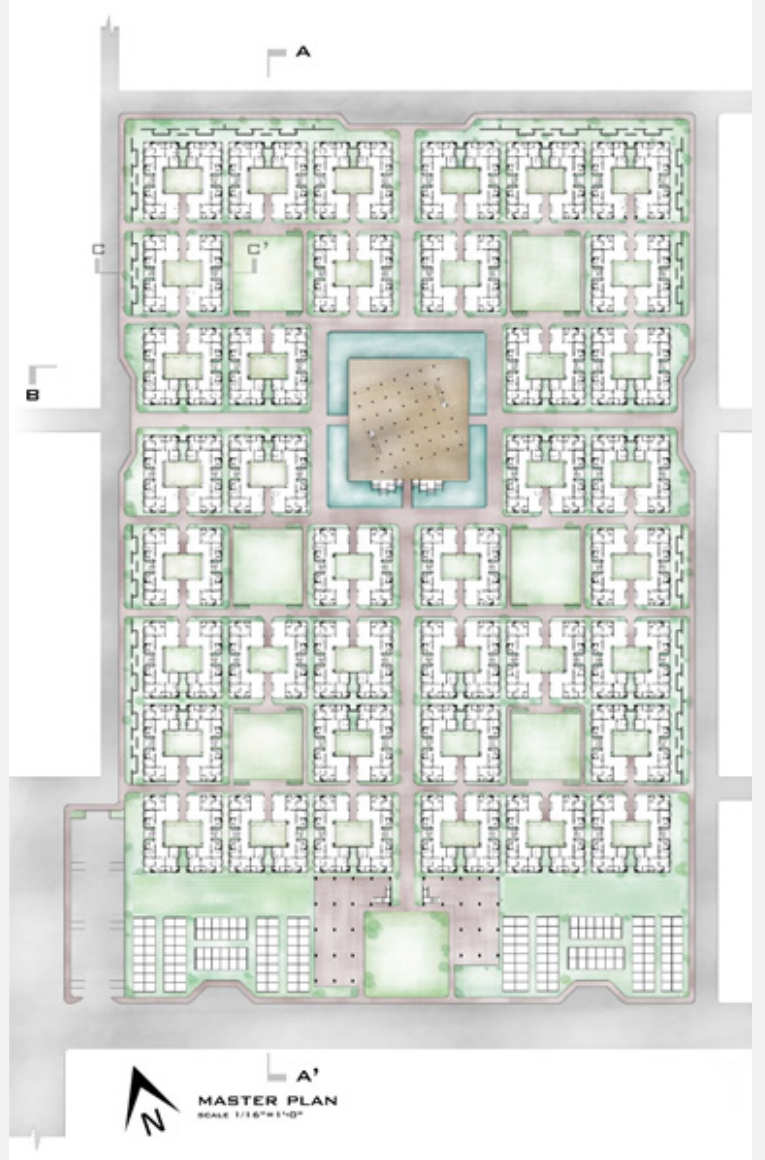

Figure 20: Master Plan of Synthesis-3. 
A green setback is separated the commercial block from the housing clusters. Community functions are located at the centre of the commercial ribbon. A parking lot is located beside the commercial zone to serve both the housing and the commercial zone. Strong axis is maintained to make the housing clusters well connected. The basic built form is derived from a square (Figure 21). Each six storied building contains twelve apartment units distributed in four blocks and two vertical circulations. The horizontal circulation spaces in each floor is much wider to use as communal space for the inhabitants. The apartment units are compact in nature to reduce the size and make them affordable besides creating more open spaces for the community living in the housing. The same room has multiple use in different time of a day (Figure 22).

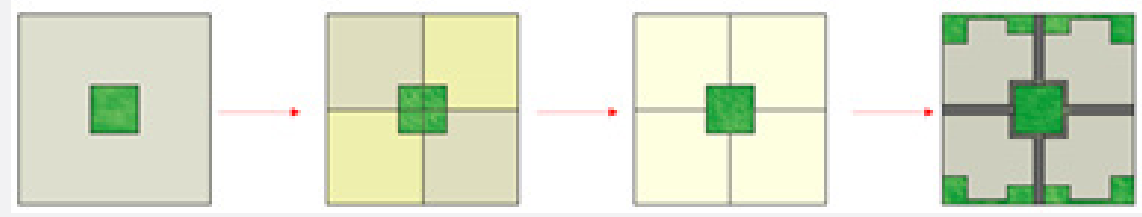

Figure 21: Generation of a Built-form from a geometric square.

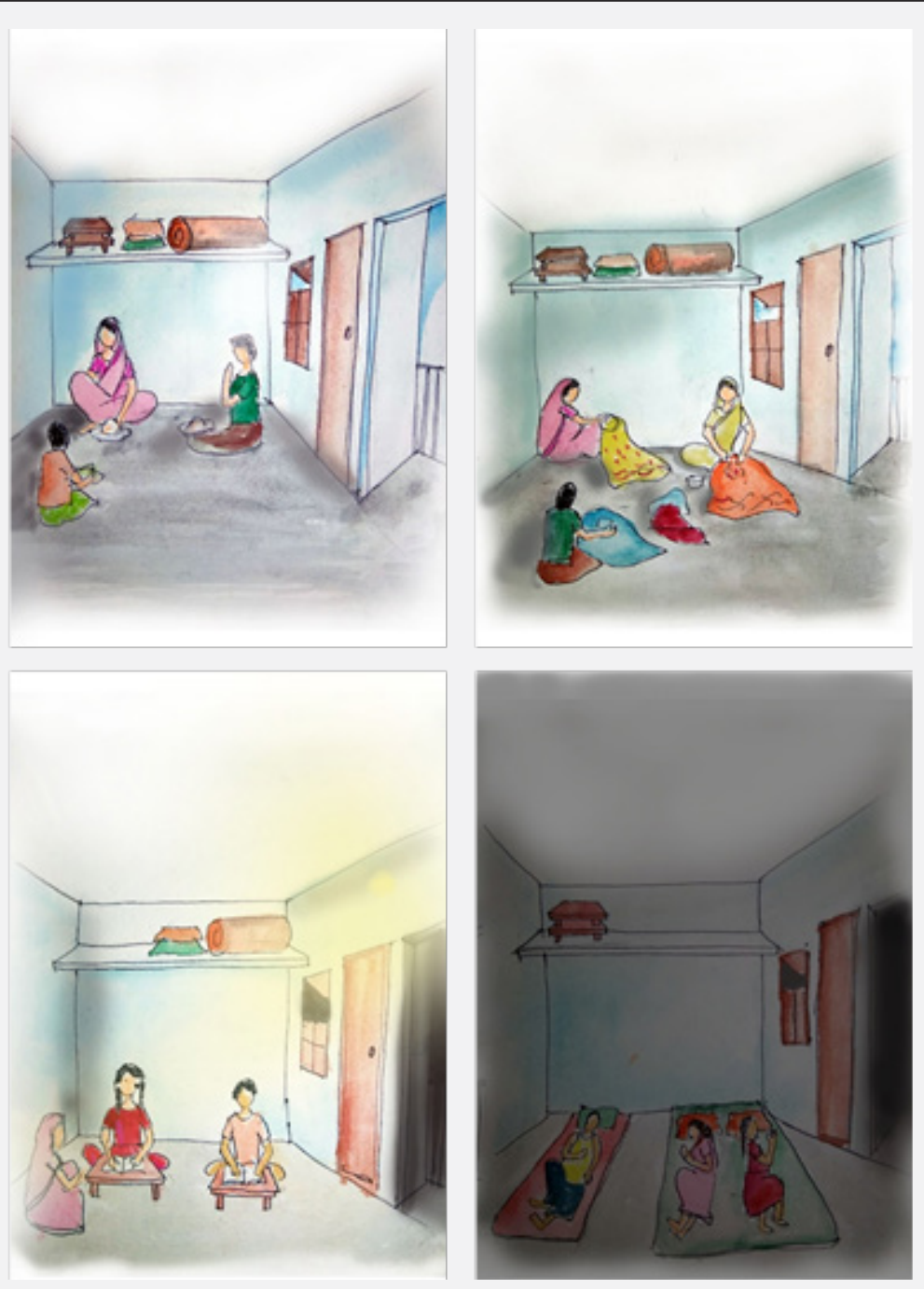

Figure 22: Different use of same room in different time in a day. 
There is a square courtyard inside the square shaped building or on the other hand it can be said that the apartment units are surrounded to a central courtyard. The green courtyard is a multipurpose place for the community (Figure 23). Multiple buildings are place in a regular grid. Some grids are remaining vacant and surrounded by pedestrian pathway and buildings after that. These vacant places are act as playground for the children and has other multipurpose communal activities. These fields are the breathing spaces for the inhabitants as well for the building themselves (Figure 24). By this approach of design, there are $42 \%$ spaces are open out of it $30 \%$ is considered as soak-able green spaces which includes courtyards, garden, plantation beside roads etc. (Figure 25 \& 26).
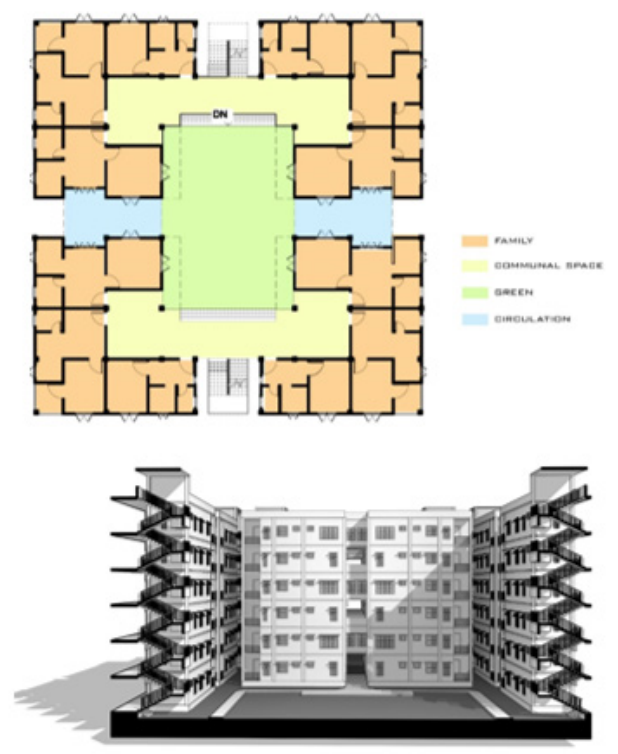

Figure 23: Floor plan (A) and sectional perspective (B) of a typical building of Synthesis-3.

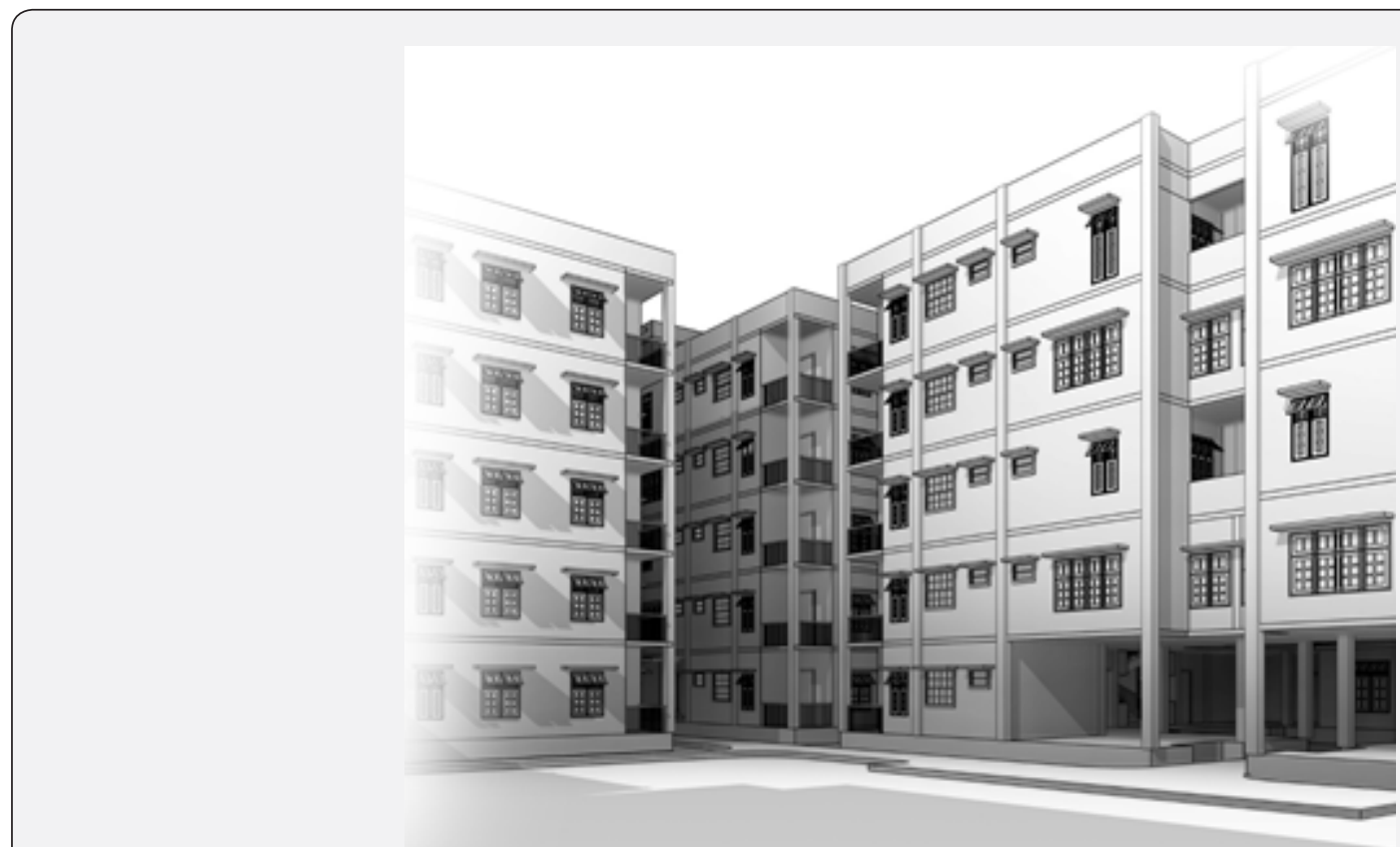

Figure 24: A courtyard surrounded by building blocks. 


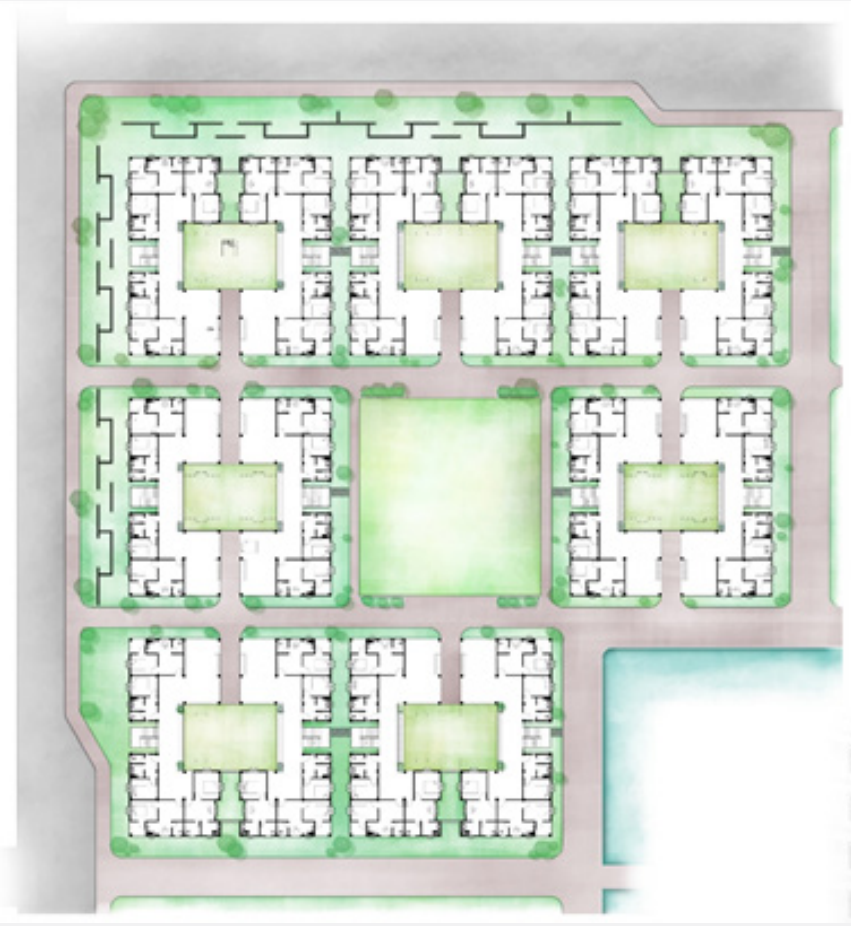

Figure 25: Plan of a cluster of Synthesis-3.

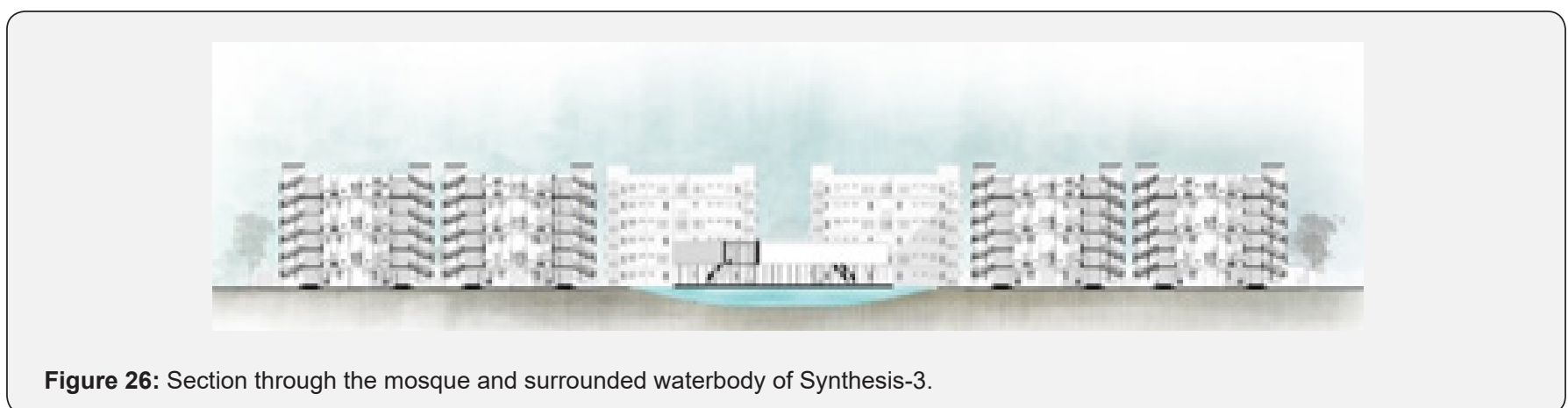

\section{Conclusion}

Traditionally, camps are built as temporary holding shelters until reconstruction phase is finalized and the displaced can go back to their homes. But after five almost five decades of its establishment Geneva camp is no more a temporary shelter inside the urban surroundings rather demands some permanent solution now for its inhabitants. However, long-term events with lasting impact are forcing us to rethink this approach to camp design.

This study suggests that camps integrating with the society in which they are placed, in terms of exchange of services, is more recent. This research aimed to increase the understanding of the approach to refugee camp design.

The main challenge is the very high population within a relatively small chunk of land. This population with land ratio exceeds all standards and practicing build codes. Another challenge is the expenditure of maintenance of such crowded settlement. As the majority of the camp population is lower middle income group if the maintenance expenditure would be beyond their means, the total idea might be failed. In such considerations the residential buildings are kept walk-up height which is a maximum of six storied. This restriction in height had the tendency to make the housing congested. By the design exercise this congestion is tried to be overcome. Open and communal spaces in different scales are introduced in many levels- which reduce the congestion tendency. Beside this breathing space is can refresh the mind of the inhabitants who are living in a confined space for decades.

Livelihood is another considerable factor for the housing. The present camp is the source of living for most of the people. These are kept in consideration to design the whole settlement. Every residential building has spaces for income generating workshops and there are zones for commercial activities and bazaar. By 
keeping these, the livelihood practice of the camp dwellers will not be hampered. It is apparent that the camps are increasingly integrated with the local community as time goes by. And the livelihood of camp dwellers also depends on this. The design approaches considered the integration of local surroundings to some extend to the newly designed settlement keeping the privacy of the settlement. Geneva camp is a place for many sociocultural activities; some of them has rich traditional and cultural values. Design approaches consider these values and tradition. All the three synthesis has sufficient spaces for social and cultural activities. These spaces sometimes have multifunctional use thorough out the year. BY these spaces camp dwellers cultural and traditional activities shall be valued.

There are some limitations of such approach of design in an Architecture design studio. The study shows that the proposed approach representing a bottom-up, community-based approach to camp design is implemented only to a limited extent, particularly in the initial implementation phase. This study provides an initial understanding of some approaches to permeant camp design, but more research is needed to provide normative advice on specific design principles. First, a natural extension of this research would be the validation of the case-driven insights with further empirical research, both in depth and breadth.

Research on camp design should also be interdisciplinary. For example, if refugee camps are to be long-term human settlements, it makes sense that urban planners and architects be an essential part of the process to provide an effective and sustainable design (Jacobs, 2017) [20]. "In the long run, refugees are an asset, not a liability - an economic benefit that can help revitalize a region, not a drain on resources" (Jacobs, 2017). This type of research can also make use of the industrial network theory for analysis of the interconnectedness between activities, actors, and resources. The social network theory provides yet another interesting avenue for future research. Furthermore, socio-political factors playing a role in camp design require knowledge from political science and the organizational theory.

The proposed approach based on longer-term, participatory solutions, meaning that refugees and the local community actively participate in camp development and operation, is gaining increased attention among governments and humanitarian organizations.

\section{Acknowledgement}

Acknowledgement to sixteen under-graduate students of the Architecture Department of Southeast University, Dhaka, Bangladesh. They are- Moukuri Mohim, Md. Arif Hossain, Ambia Akter, Mahmudul Hasan, Umme Sayeda Eva, Fairooz Nawar Rangan, Halima Tamrin, Somayea, Anija Kabir, Nahidur Rahman, Prome Roy Chaity, Md. Mehadi Hasan, Apurba Sarker, Rhain Afroz, Ahmad Tanvir and Md. Khalek Masud.

\section{References}

1. Rashid M (2019) Transformation of Housing in Low-income Settlement: A Study of Domestic Spaces in Ershad Nagar Resettlement Camp. Nakhara: Journal of Environmental Design and Planning, 16: 119-146.

2. Kinyungu AN (2004) Public-Sector Partnerships in the Servicing of Land and Provision of Housing for Low-income Groups in Harare: Experiences and Lessons Learnt 1990-1996. RICS Foundation, UK.BBC News. 19 May 2008. Citizenship for Bihari refugees. BBC News. 19 May 2008.

3. Mowla QA, Afrin S (2008) Evaluating the Housing Situation for the Urban Poor in Dhaka. The Jahangirnagar Review 32: 91-104.

4. Kennedy J (2008) Structure for the displaced: service and identify in refugee settlements. PhD thesis, Delft Technical University, Delft.

5. Pelin T (2016) Architecture in crisis: exception as a form of decay. Architectural Research Quarterly 92: 114-117.

6. Ramadan A (2013) Spatialising the refugee camp. Transactions of the Institute of British Geographers 38(1): 65-77.

7. Beehner L (2015) Are Syria's do-it-yourself refugee's outliers or examples of a new norm? Journal of International Affairs 68(2): 157175.

8. Dozema M (2016) Rethinking the refugee camp.

9. Gibson E (2016) Humanitarian experts propose turning refugee camps into enterprise zones called 'refugee cities", Concept paper "Refugee Cities: Expanding Options for Displaced People Through Special Economic Zones. A project of Refugee Cities in Partnership with IPA Switchboard, HTIL, Living Design Lab, Middle East Investment Initiative, November.

10. Dzeamisi MK (2008) Refugees, the UNHCR and host governments as stake-holders in the transformation of refugee communities: a study into the Buduburam refugee camp in Ghana. International Journal of Migration, Health and Social Care 4(1): 28-41.

11. Jahre M, Kembro J, Adjahossou A, Altay N (2018) Approaches to the design of refugee camps: An empirical study in Kenya, Ethiopia, Greece, and Turkey. Journal of Humanitarian Logistics and Supply Chain Management 8(3): 323-345.

12. Kleinschmidt K (2015) Refugee camps are the 'cities of tomorrow', says humanitarian-aid expert.

13. Kennedy J (2005) Challenging camp design guidelines. Forced Migration Review 23: 46-47.

14. Wikipedia (2019) Stranded Pakistanis in Bangladesh.

15. Shoulder H (2011) Housing and Land Rights: The Camp-Dwelling Urdu-Speaking Community in Bangladesh. Refugee and Migratory Movements Research Unit (RMMRU),

16. The Daily Star (2018) Geneva camp in Dhaka's Muhammadpur

17. Rashid M (2020) Identification of Housing Crisis in a Confined Settlement: A study of Mohammadpur Geneva camp. Journal of Creative Space, Chitkara University, India 7(2): 125-142.

18. UN-HABITAT - United Nations Human Settlements Programme (2003) The challenge of slums: global report on human settlement.

19. The State of the World's Refugees (2000) Fifty Years of Humanitarian Action - Chapter 3: Rupture in South Asia. Oxford University Press (OUP), p. 14.

20. Jacobs K (2017) What's next: rethinking the refugee camp. Architect 106(1): 78-115. 
(C) This work is licensed under Creative CC) Commons Attribution 4.0 Licens BY DOI: 10.19080/TTSR.2020.04.555638
Your next submission with Juniper Publishers will reach you the below assets

- Quality Editorial service

- Swift Peer Review

- Reprints availability

- E-prints Service

- Manuscript Podcast for convenient understanding

- Global attainment for your research

- Manuscript accessibility in different formats

( Pdf, E-pub, Full Text, Audio)

- Unceasing customer service

Track the below URL for one-step submission https://juniperpublishers.com/online-submission.php 